\title{
Contribution of heat outputs from high- and low-temperature hydrothermal sources to the neutrally buoyant plume at the TAG hydrothermal mound, Mid-Atlantic Ridge
}

\author{
Shusaku Goto ${ }^{1}$, Toshitaka Gamo ${ }^{2}$, Hitoshi Chiba ${ }^{3}$, Kantaro Fujioka $^{4}$, and Kyohiko Mitsuzawa ${ }^{5}$ \\ ${ }^{1}$ Institute for Geo-Resources and Environment, National Institute of Advanced Industrial Science and Technology (AIST), \\ AIST Tsukuba Central 7, 1-1-1 Higashi, Tsukuba, Ibaraki 305-8567, Japan \\ ${ }^{2}$ Ocean Research Institute, the University of Tokyo, 1-15-1 Minami-dai, Nakano-ku, Tokyo 164-8639, Japan \\ ${ }^{3}$ Department of Earth Sciences, Okayama University, 3-1-1 Tsushima-naka, Okayama, Okayama 700-8530, Japan \\ ${ }^{4}$ Marine-Earth Data and Information Department, Japan Agency for Marine-Earth Science and Technology, \\ 3173-25 Showa-machi, Kanazawa-ku, Yokohama, Kanagawa 236-0001, Japan \\ ${ }^{5}$ Super Computer System Planning and Operation Department, Japan Agency for Marine-Earth Science and Technology, \\ 3173-25 Showa-machi, Kanazawa-ku, Yokohama, Kanagawa 236-0001, Japan
}

(Received March 16, 2007; Revised July 17, 2007; Accepted August 23, 2007; Online published October 19, 2007)

\begin{abstract}
We provide an estimation of the heat output necessary to generate the neutrally buoyant plume above the TAG hydrothermal mound, Mid-Atlantic Ridge, located at $26^{\circ} \mathrm{N}$, using a model of plume rise in a density-stratified environment with crossflow. The estimated heat output is $460 \pm 40 \mathrm{MW}$. Previous studies have estimated that the heat outputs from high-temperature hydrothermal discharge and low-temperature diffuse flow at the TAG hydrothermal mound are $90 \pm 20 \mathrm{MW}$ and at least $780 \mathrm{MW}$, respectively. Consequently, the contribution of diffuse flow to make the neutrally buoyant plume is $370 \pm 60 \mathrm{MW}$, which accounts for approximately $80 \%$ of the heat output to the neutrally buoyant plume. As this contribution is less than $50 \%$ of the total heat output from the diffuse flow, it is likely that more than $50 \%$ of the heat output from the diffuse flow dissipates in the ambient current.
\end{abstract}

Key words: Heat output, neutrally buoyant plume, high-temperature hydrothermal discharge, low-temperature diffuse flow, TAG hydrothermal mound.

\section{Introduction}

Heat supplied to mid-ocean ridges from the mantle causes hydrothermal circulation within the oceanic crust (e.g., Kelley et al., 2002; Kawada et al., 2004). One expression of this circulation takes the form of the hightemperature hydrothermal fluid discharged from chimneys. This fluid will rise because its buoyancy is positive relative to that of ambient seawater. As this fluid rises, it produces a "buoyant plume" (e.g., Morton et al., 1956), which rises to a height at which the positive buoyancy of the fluid vanishes; at this point, it becomes a "neutrally buoyant plume".

The height of a neutrally buoyant plume depends on ambient temperature and salinity gradients, crossflow velocity, and the heat output at the seafloor. Heat outputs from hydrothermal systems have been estimated based on the nature of the neutrally buoyant plume as well as from direct measurements at the seafloor. For example, on the Endeavour segment of the Juan de Fuca Ridge, heat output estimated from neutrally buoyant plumes exceeds $1000 \mathrm{MW}$ (e.g., Baker and Massoth, 1987). In contrast, total heat output associated with high-temperature hydrothermal discharge on the Endeavor segment is estimated as only a few hundred

Copyright (c) The Society of Geomagnetism and Earth, Planetary and Space Sciences (SGEPSS); The Seismological Society of Japan; The Volcanological Society of Japan; The Geodetic Society of Japan; The Japanese Society for Planetary Sciences; TERRAPUB.
MW (Bemis et al., 1993; Ginster et al., 1994). A probable source of such differences is the contribution of lowtemperature diffuse outputs to the neutrally buoyant plume. However, the size of the contribution of the heat released from the diffuse venting sources to the neutrally buoyant plume is still unclear.

The TAG hydrothermal mound of the Mid-Atlantic Ridge, located at $26^{\circ} \mathrm{N}$ (Fig. 1), is an extensively studied active hydrothermal system. This mound is isolated from other high-temperature hydrothermally active sites, and a neutrally buoyant plume exists above the mound (Rudnicki and Elderfield, 1992). Active, high- and lowtemperature hydrothermal sources have been identified in the well-mapped area (e.g., Tivey et al., 1995), and heat outputs from high-temperature hydrothermal discharge and low-temperature diffuse flow have been estimated. Goto et al. (2003) analyzed temperatures measured with three 50-m-high thermistor arrays that were deployed around the vents of the main black smoker chimney at this mound from August 1994 to March 1995. By selecting plume temperature profiles inferred to be less affected by ambient current and using a model of plume rise in the stagnant condition of Morton et al. (1956), these researchers estimated the heat output from the chimney to be $90 \pm 20 \mathrm{MW}$ (error: $95 \%$ confidence limit) during the first month. Schultz and Elderfield (1997) deployed a diffuse flow monitoring system on 


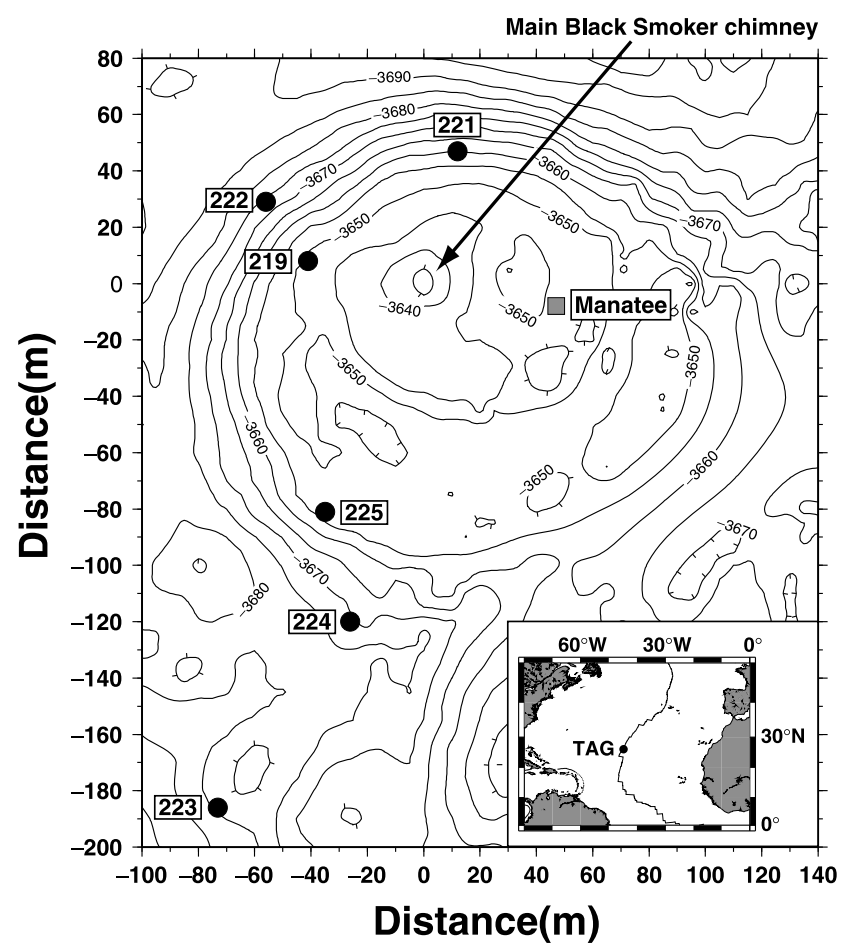

Fig. 1. Bathymetric map of the TAG hydrothermal mound (bathymetric data from Humphris and Kleinrock (1996)). Gray square indicates the position of the Manatee, solid circles are the positions where Shinkai 6500 passed through the TAG neutrally buoyant plume. Insert is an index map of the location of the TAG hydrothermal mound.

the TAG hydrothermal mound in September 1994 and monitored the temperature and velocity of the low-temperature diffuse flow. Based on their measurements, they estimated a lower limit on the total heat output associated with a diffuse flow at $780 \mathrm{MW}$.

In this study, we estimated the heat output that generates the neutrally buoyant plume above the TAG hydrothermal mound from CTDV (conductivity, temperature, depth, and sound velocity) and current data, using a model of plume rise in a density-stratified condition with crossflow (Middleton, 1986). Our new estimate is then used to estimate the heat output from low-temperature sources that contribute to the neutrally buoyant plume by comparing with previous heat output estimates.

\section{Instrumentation}

\subsection{CTDV system of Shinkai 6500}

The submersible Shinkai 6500 has a CTDV measurement system (Tsurumi Seiki Co., Japan) that it uses to survey oceanographic parameters in the water column. The accuracies of these sensors are $\pm 0.02 \mathrm{mS} \mathrm{cm}^{-1}$ for conductivity, $\pm 0.02 \mathrm{~K}$ for temperature, $\pm 0.25 \mathrm{dbar}\left(2.5 \times 10^{3} \mathrm{~Pa}\right)$ for pressure, and $\pm 0.2 \mathrm{~m} \mathrm{~s}^{-1}$ for sound velocity.

During July-August 1994, the MODE'94 Leg 2 cruise was carried out to survey hydrothermal activity at the TAG hydrothermal mound (Fujioka et al., 1997). During this cruise, Shinkai 6500 carried out 15 dives, and CTDV data were obtained continuously during the operations. The sampling intervals varied between 1 and $5 \mathrm{~s}$.

\subsection{Stationary deep seafloor observatory "Manatee"}

The long-term deep seafloor observatory platform "Manatee" contains various instruments to monitor seafloor hydrothermal activity (Fujioka et al., 1997). In this study, current data measured with the electromagnetic current meter (ACM-8M; Alec Electronics) are used. The accuracy and resolution are $\pm 2 \%$ and $0.1 \mathrm{~cm} \mathrm{~s}^{-1}$ in current speed and $\pm 2^{\circ}$ and $0.1^{\circ}$ in direction, respectively. During August 621, 1994, Manatee was deployed on the NE part of the TAG hydrothermal mound (Fig. 1); the current meter was located approximately $3 \mathrm{~m}$ above the seafloor (sampling interval: $30 \mathrm{~min})$.

\section{Plume Model}

We assume that a buoyant plume rises in a densitystratified seawater with a crossflow of constant velocity and that the otherwise vertically ascending plume is "bent" by the crossflow. The maximum rise height at the center of the plume $z_{\max }$ is (Middleton, 1986)

$$
z_{\max }=3.8\left(\frac{F_{s}}{U N^{2}}\right)^{1 / 3}
$$

where $U$ is the crossflow velocity and $N$ is the BruntVäisälä frequency. $F_{S}$ is the initial buoyancy flux defined as

$$
F_{s}=b_{0}^{2} w_{0} p_{0}=\frac{V_{0}}{\pi} p_{0}
$$

where $b_{0}$ is the radius of plume source, $w_{0}, V_{0}$, and $p_{0}$ are the velocity, volume flux, and buoyancy, respectively, of the plume fluid at the source exit. The buoyancy $p_{0}$ is expressed as (Morton et al., 1956)

$$
p_{0}=\alpha g \Delta T
$$

where $g$ is the gravity acceleration, $\alpha$ is the thermal expansion coefficient of plume fluid, and $\Delta T$ is the temperature difference between plume fluid and ambient seawater. Heat output $H$ is given as

$$
H=\rho_{0} c_{p} V_{0} \Delta T
$$

where $\rho_{0}$ and $c_{p}$ are the density and specific heat, respectively, of the plume fluid. Using Eqs. (2) and (3), Eq. (4) is re-expressed as

$$
H=\frac{\pi \rho_{0} c_{p} F_{s}}{\alpha g}
$$

The estimate of heat output to make the TAG neutrally buoyant plume using the above equations is as follows. First, $F_{s}$ is estimated from $z_{\max }$ obtained from CTDV data and $U$ measured with current meter using Eq. (1). Using Eq. (5), $H$ is then calculated from the estimated $F_{s}$. In this calculation, we assume $\rho_{0}=1043 \mathrm{~kg} \mathrm{~m}^{-3}, c_{p}=$ $4100 \mathrm{~J} \mathrm{~kg}^{-1} \mathrm{~K}^{-1}, \alpha=1.48 \times 10^{-4 \circ} \mathrm{C}^{-1}$, and $g=9.8 \mathrm{~m} \mathrm{~s}^{-2}$. Goto et al. (2003) estimated $N$ from six CTDV profiles that show no influence from the TAG neutral buoyant plume, as shown in Fig. 2(a) and Fig. 3(a) (see Section 4.2 in detail). The estimated $N$ is a constant value, $8.96 \pm 0.37 \times 10^{-4} \mathrm{~s}^{-1}$. In this study, we use $N=8.96 \times 10^{-4} \mathrm{~s}^{-1}$ for estimating heat output. 


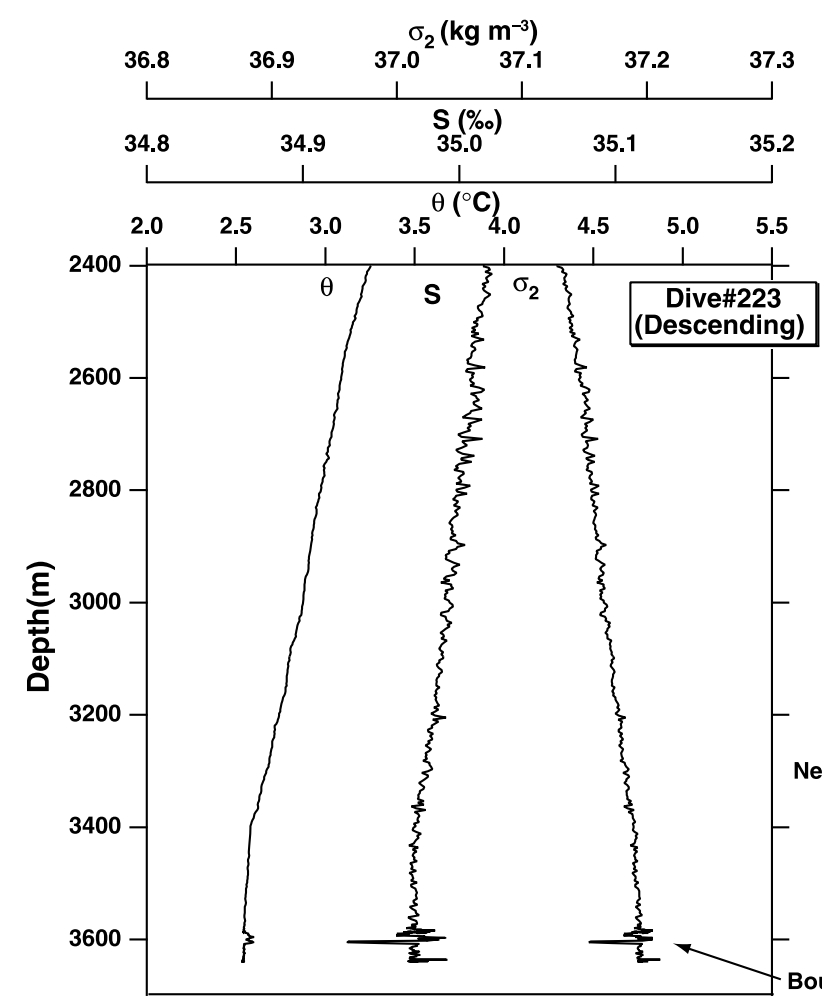

(a)

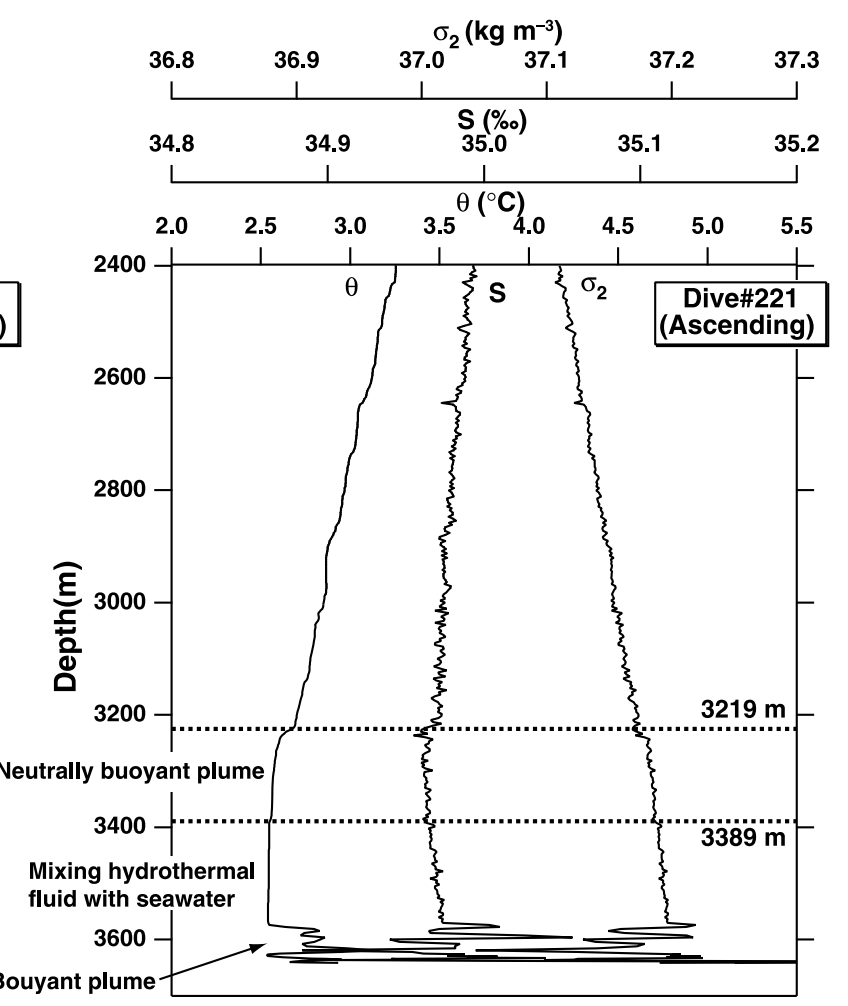

(b)

Fig. 2. Vertical profiles of potential temperature $\theta$, salinity $S$, and potential density $\sigma_{2}$. (a) Profiles of $\theta, S$, and $\sigma_{2}$ in the ambient water column (Shinkai 6500 Dive no. 223). (b) Profiles of $\theta, S$, and $\sigma_{2}$ in the water column in the case that Shinkai 6500 passed through the TAG neutrally buoyant plume (Shinkai 6500 Dive no. 221).

\section{Measurements}

\subsection{Bottom-water current at the TAG hydrothermal} mound

Manatee monitored current direction and velocity for 16 days (August 6-21, 1994). As the nature of the current has been discussed by Kinoshita et al. (1998) in detail, we review it here only briefly. In the monitoring period, the bottom-current flow from east to northwest was commonly measured. However, the variation in direction, observed periodically at 12-h intervals, is asymmetric in that it changes rapidly from westward to eastward, then gradually returns to westward. The minimum, maximum, and average current velocities over the measurement period are 1.0, 28.3, and $7.3 \mathrm{~cm} \mathrm{~s}^{-1}$, respectively. Fourier analysis of current velocity indicates that the period of the most conspicuous peak in the spectral density is about $12 \mathrm{~h}$. Therefore, the bottom-current flow was probably mostly modulated by the semi-diurnal ocean tides in the region.

\subsection{Water column survey using CTDV system of Shinkai 6500}

Temperature and salinity in the water column decrease with depth in the deep Atlantic Ocean. Speer and Rona (1989) showed that the temperature and salinity of the neutrally buoyant plume in the deep Atlantic Ocean are cooler and fresher, respectively, than those of ambient seawater at the same depths. The reason for this is that the plume fluid is diluted with ambient seawater during its rise and this ambient seawater is fresher and colder than the neutrally buoyant height. CTD profiles taken within a lateral distance of $50 \mathrm{~m}$ from the center of the high temperature venting of the TAG hydrothermal mound showed negative temperature and salinity anomalies in the intervals where the TAG neutrally buoyant plume exists (Rudnicki and Elderfield, 1992).

Figure 2 shows examples of vertical profiles of potential temperature $\theta$, salinity $S$, and potential density $\sigma_{2}$ that were measured with the CTDV system onboard Shinkai 6500. To identify the TAG neutrally buoyant plume in such profiles, we used a T-S diagram, which is a tool used when studying the mixing of seawater with hydrothermal fluid. In Fig. 2(a), $\sigma_{2}$ increases monotonically with depth, and both $\theta$ and $S$ decrease with depth in the water column shallower than $3580 \mathrm{~m}$. Figure 3(a) shows the T-S diagram for $\theta$ and $S$ used in Fig. 2(a). There is no significant signal that shows a mixing of seawater with hydrothermal fluid that would be representative of the background profiles in the depth interval. On the other hand, there are variable anomalies of $\theta$, $S$, and $\sigma_{2}$ in the water column between the depths of 3580 and $3610 \mathrm{~m}$, suggesting that Shinkai 6500 passed through a buoyant plume derived from the TAG hydrothermal mound.

Figure 2(b) shows the $\theta, S$, and $\sigma_{2}$ profiles obtained by Shinkai 6500 as it passed through the neutrally buoyant plume. The $\theta$ in the water column at depths between 3219 and $3389 \mathrm{~m}$ can be seen to be cooler than that extrapolated from the trend of the profile over the interval. Furthermore, $S$ in the water column in the same depth interval is fresher than that expected from the trend over the interval. As shown in Fig. 3(a), the $\theta-S$ relation shows significant deviations from the background trend within the depth interval where cooler $\theta$ and fresher $S$ are observed, indicating that the neutrally buoyant plume occupied the depth interval. 

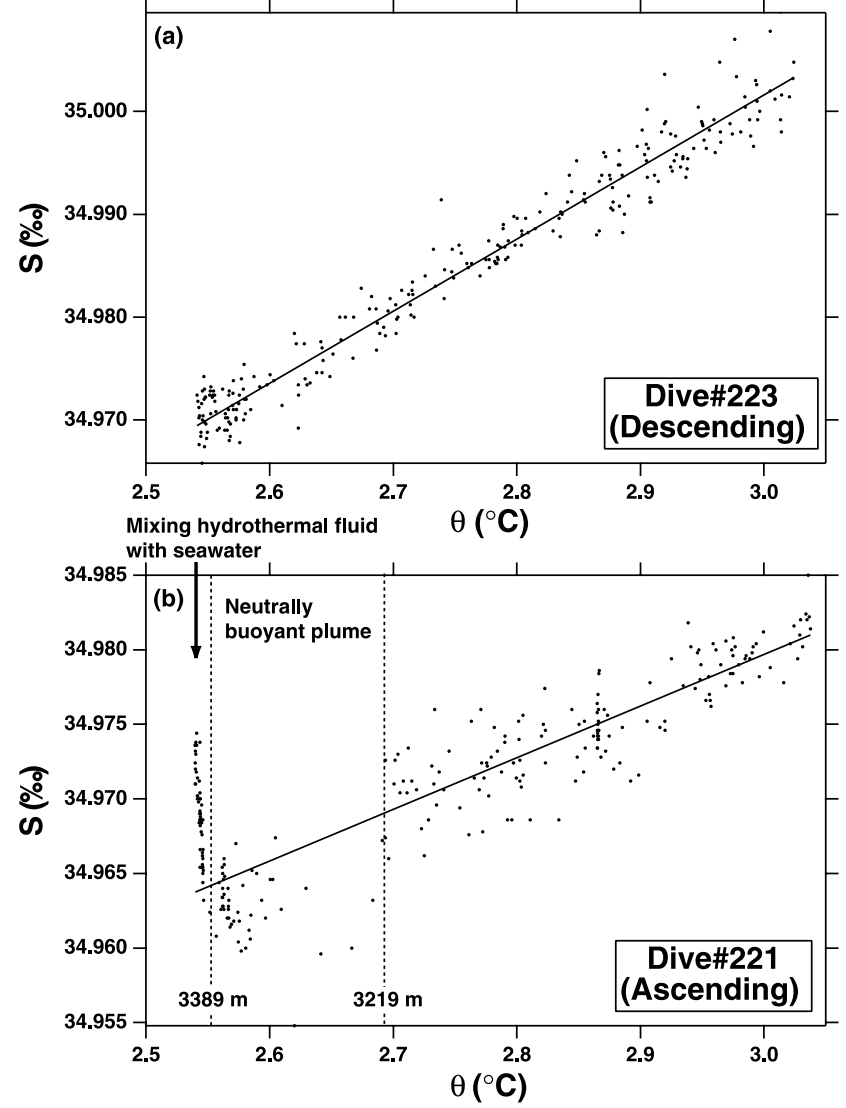

Fig. 3. Plots of the $\theta-S$ relation. (a) $\theta-S$ relation in water column between 2700 and $3580 \mathrm{~m}$ in Fig. 2. (b) $\theta-S$ relation in water column between 2700 and $3570 \mathrm{~m}$ in Fig. 2(b).

In Fig. 2(b), there are various anomalies of $\theta, S$, and $\sigma_{2}$ in the water column at depths of greater than $3570 \mathrm{~m}$, suggesting the presence of a buoyant plume from the TAG hydrothermal mound. As mentioned above, salinity in the water column in the deep Atlantic Ocean decreases with depth. However, $S$ in the water column between 3389 and $3570 \mathrm{~m}$ increases with depth. The $\theta-S$ relation within this interval is quite different from those for the background and TAG neutrally buoyant plume (Fig. 3(b)). The salinity of hydrothermal fluid of the TAG hydrothermal mound is higher than that of ambient seawater (James and Elderfield, 1996). Thus, the fluid within this interval most likely consists of a mixture of hydrothermal fluid and ambient seawater.

\section{Results}

To identify the TAG neutrally buoyant plume from anomalies in the $\theta$ and $S$ profiles (e.g., Fig. 2(b)), we used the criterion that the position where Shinkai 6500 passed through the neutrally buoyant plume is within $200 \mathrm{~m}$ of the main venting at the mound (Fig. 1); otherwise, anomalies of $\theta$ and $S$ are too small as a result of mixing with ambient seawater. On this basis, six pairs of upper and lower boundary depths of the TAG neutrally buoyant plume were identified. These depths were then converted into heights above the TAG hydrothermal mound. The heights of the upper, lower, and their middle points of the observed TAG neutrally buoyant plume are given in Table 1 . The average current velocities measured with Manatee within $1 \mathrm{~h}$ before
Table 1. Heights of the TAG neutrally buoyant plume and crossflow velocities.

\begin{tabular}{|c|c|c|c|c|}
\hline \multirow{2}{*}{$\begin{array}{c}\text { Shinkai } 6500 \\
\text { Dive } \\
\text { No. }\end{array}$} & \multicolumn{3}{|c|}{ Height $(m)^{\mathrm{a}}$} & \multirow{2}{*}{$\begin{array}{c}\text { Crossflow } \\
\text { velocity } \\
\left(\mathrm{cm} \mathrm{s}^{-1}\right)\end{array}$} \\
\hline & $\begin{array}{c}\text { Upper } \\
\text { boundary }\end{array}$ & $\begin{array}{c}\text { Lower } \\
\text { boundary }\end{array}$ & $\begin{array}{l}\text { Middle } \\
\text { point }\end{array}$ & \\
\hline $\begin{array}{c}219 \\
\text { (ascending) }\end{array}$ & 406.2 & 228.8 & 317.5 & $10.2 \pm 0.6$ \\
\hline $\begin{array}{c}221 \\
\text { (ascending) }\end{array}$ & 430.8 & 261.5 & 346.2 & $8.9 \pm 0.3$ \\
\hline $\begin{array}{c}222 \\
\text { (ascending) }\end{array}$ & 460.3 & 320.5 & 390.4 & $6.8 \pm 0.6$ \\
\hline $\begin{array}{c}223 \\
\text { (ascending) }\end{array}$ & 446.0 & 256.2 & 351.1 & $7.0 \pm 0.4$ \\
\hline $\begin{array}{c}224 \\
\text { (ascending) }\end{array}$ & 497.5 & 282.8 & 390.2 & $6.1 \pm 0.9$ \\
\hline $\begin{array}{c}225 \\
\text { (ascending) }\end{array}$ & 438.0 & 282.1 & 360.1 & $6.4 \pm 0.3$ \\
\hline
\end{tabular}

${ }^{\text {a }}$ Height to the water depth of the neutrally buoyant plume above the upper terrace of the TAG hydrothermal mound (depth: $3650 \mathrm{~m}$ )

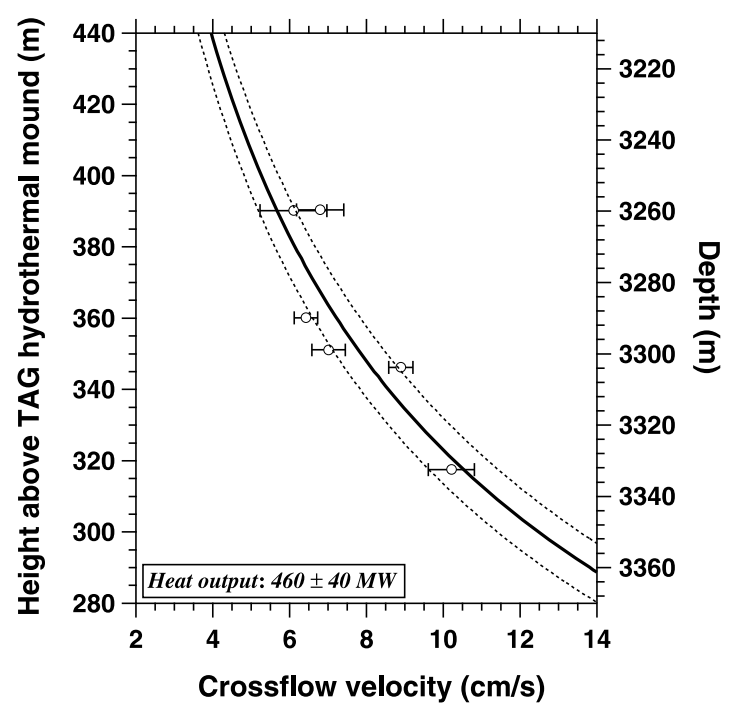

Fig. 4. Height of the middle point of the observed TAG neutrally buoyant plume versus current velocity. The right-side axis indicates the depth corresponding to the height above the TAG hydrothermal mound in the left-side axis. The thick solid curve is the best fitting line to estimate heat output to make the TAG neutrally buoyant plume. Dashed lines indicate $95 \%$ confidence limits on the best fitting line.

Shinkai 6500 passed through the neutrally buoyant plume are also listed in Table 1. Figure 4 shows the plots of the middle point height of the TAG neutrally buoyant plume versus current velocity. The height of the neutrally buoyant plume decreases with increasing current velocity.

We assume that the observed heights of the middle point of the TAG neutrally buoyant plume correspond to those of the plume center in response to the observed current velocities. Using the equations shown in Section 3, we estimated a heat output to determine the neutrally buoyant plume from the heights and current velocities. Figure 4 shows the plot of the best-fit curve and its $95 \%$ confidence limits. Our best estimate of the heat output is $460 \pm 40 \mathrm{MW}$ (error: 95\% confidence limit), which is significantly large compared to the heat output of $90 \pm 20 \mathrm{MW}$ from the high-temperature hydrothermal discharge of the TAG hydrothermal mound (Goto et al., 2003). 


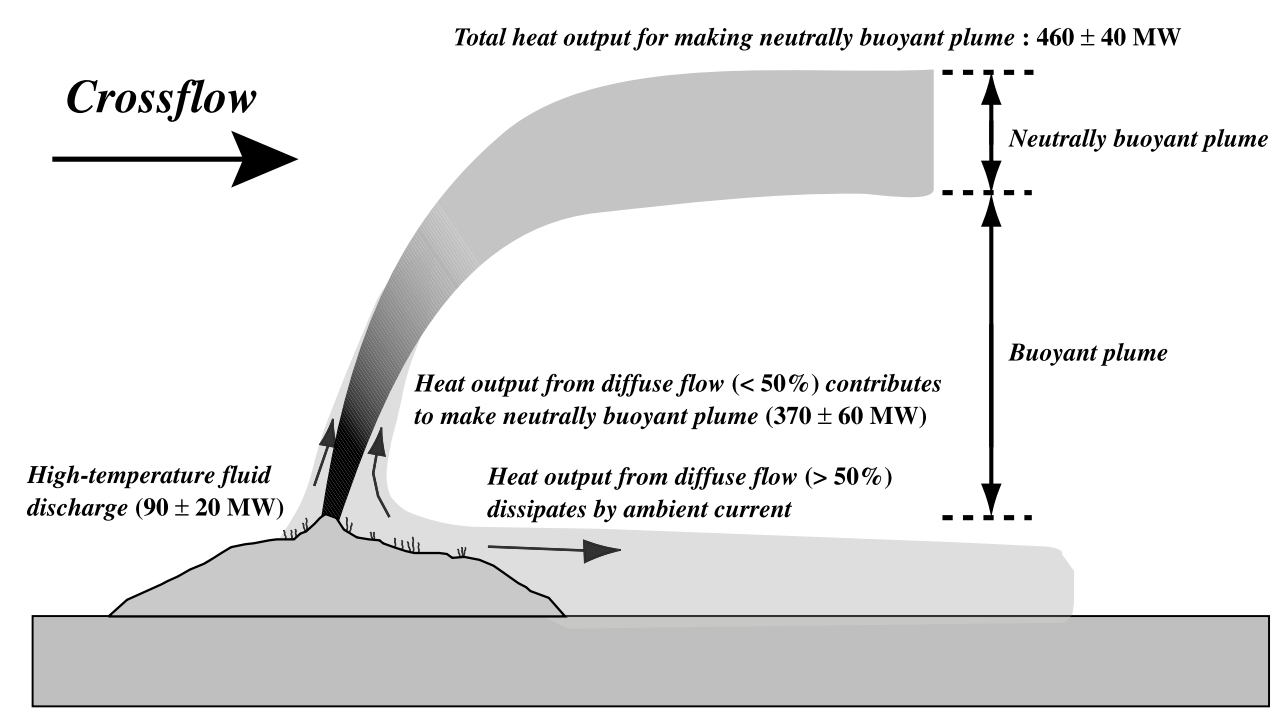

Fig. 5. Schematic model of partitioning of heat outputs from high- temperature hydrothermal discharge and low-temperature diffuse flow at the TAG hydrothermal mound.

There are a number of possible uncertainties in the observed $U, z_{\max }$, and $N$ that are derived from potential uncertainties in the measurement positions and sampling intervals. Here we evaluate how the possible uncertainties of these parameters affect our heat output estimate. We assumed in the estimate of heat output that the observed middle point heights of the TAG neutrally buoyant plume correspond to those of the plume center. A height uncertainty of $\pm 10 \mathrm{~m}$ will result in an uncertainty of approximately $9 \%$ in the heat output estimate. Plume rise depends sensitively on the density stratification in the water column. In this study, we used an $N$ of ambient seawater that was estimated at $8.96 \pm 0.37 \times 10^{-4} \mathrm{~s}^{-1}$ (Goto et al., 2003). The estimation error of $N$ will result in an error of $9 \%$ in the heat output estimate. The current data used in the heat output estimate was measured at approximately $3 \mathrm{~m}$ above the seafloor. There is a possibility that the velocity of the current higher in the water column was different from that measured. Assuming current velocity values that differed from the measured ones by $\pm 10 \%$, we then calculated heat output. Consequently, the calculation yields heat output values that differ by $\pm 10 \%$ from our best estimate.

\section{Discussion and Conclusions}

Goto et al. (2003) estimated the heat output from the high-temperature hydrothermal discharge at the TAG hydrothermal mound in August 1994 to be $90 \pm 20$ MW (error: 95\% confidence limit). This heat output is only 14-26\% of that estimated from the TAG neutrally buoyant plume $(460 \pm 40 \mathrm{MW})$. Lavelle and Wetzler (1999) examined $\mathrm{Al}$ concentration distributions in the TAG main plume by three-dimensional plume modeling that takes crossflow into account and compared the results with $\mathrm{Al}$ concentration data obtained near the TAG hydrothermal mound (Lunel et al., 1990). Lavelle and Wetzler (1999) indicated that the contribution of the $\mathrm{Al}$ concentration anomaly in the neutrally buoyant plume from low-temperature diffuse flow is much greater than that from the high-temperature hydrothermal discharge. Thus, we conclude that a heat out- put from diffuse sources ( $370 \pm 60 \mathrm{MW})$ accounts for the difference between the heat outputs estimated by Goto et al. (2003) and this study. This contribution from diffuse sources is approximately $80 \%$ of the heat output to the neutrally buoyant plume.

What proportion of the heat output from the diffuse venting sources contributes to the TAG neutrally buoyant plume? Schultz and Elderfield (1997) estimated the lower limit on the total heat output associated with lowtemperature diffuse flow to be $780 \mathrm{MW}$. Our estimation of the contribution of heat output from the diffuse venting sources to make the neutrally buoyant plume is less than $50 \%$ of the lower limit on the heat output by Schultz and Elderfield (1997). Lunel et al. (1990) reported that bottomwater sampled approximately $50 \mathrm{~m}$ above the bottom and 140-200 $\mathrm{m}$ away from the TAG hydrothermal mound has an anomalously higher Al concentration than the background. Based on three-dimensional hydrothermal plume modeling that takes crossflow into account, Lavelle and Wetzler (1999) suggested that the Al concentration anomalies could be explained by a diffuse venting source that drifts horizontally with ambient current.

Figure 5 shows a heat output model of the TAG hydrothermal mound by integrating the results of Goto et al. (2003), Schultz and Elderfield (1997), and this study. This model indicates that whereas less than $50 \%$ of the heat from low-temperature diffuse venting sources is incorporated into the TAG neutrally buoyant plume, the heat of the remaining of $50 \%$ or more is dissipated by the ambient current.

Acknowledgments. The authors thank C. G. Wheat for his discussion on the estimate of heat output from the neutrally buoyant plume. The authors also thank R. P. Von Herzen, M. Kinoshita and one anonymous reviewer for critical reading and improvement of the manuscript. CTDV and Shinkai 6500 navigation data were provided by the Japan Agency for Marine-Earth Science and Technology. This study was supported partially by the Ridge Flux Project of the Science and Technology Agency, Japan. 


\section{References}

Baker, E. T. and G. J. Massoth, Characteristics of hydrothermal plumes from two vent fields on the Juan de Fuca Ridge, northeast Pacific Ocean, Earth Planet. Sci. Lett., 85, 59-73, 1987.

Bemis, K. G., R. P. Von Herzen, and M. J. Mottl, Geothermal heat flux from hydrothermal plumes on the Juan de Fuca Ridge, J. Geophys. Res., 98, 6351-6365, 1993.

Fujioka, K., K. Kobayashi, K. Kato, M. Aoki, K. Mitsuzawa, M. Kinoshita, and A. Nishizawa, Tide-related variability of TAG hydrothermal activity observed by deep-sea monitoring system and OBSH, Earth Planet. Sci. Lett., 153, 239-250, 1997.

Ginster, U., M. J. Mottl, and R. P. Von Herzen, Heat flux from black smokers on the Endeavour and Cleft segments, Juan de Fuca Ridge, J. Geophys. Res., 99, 4937-4950, 1994.

Goto, S., M. Kinoshita, A. Schultz, and R. P. Von Herzen, Estimate of heat flux and its temporal variation at the TAG hydrothermal mound, Mid-Atlantic Ridge $26^{\circ} \mathrm{N}$, J. Geophys. Res., 108, 2434, doi:1029/ 2001JB000703, 2003.

Humphris, S. E. and M. C. Kleinrock, Detailed morphology of the TAG active hydrothermal mound: Insights into its formation and growth, Geophys. Res. Lett., 23, 3443-3446, 1996.

James, R. H. and H. Elderfield, Chemistry of ore-forming fluids and mineral formation rates in an active hydrothermal sulfide deposit on the Mid-Atlantic Ridge, Geology, 24, 1147-1150, 1996.

Kawada, Y., S. Yoshida, and S. Watanabe, Numerical simulations of midocean ridge hydrothermal circulation including the phase separation of seawater, Earth Planets Space, 56, 193-215, 2004.

Kelley, D. S., J. A. Baross, and J. R. Delaney, Volcanoes, fluids, and life at mid-ocean ridge spreading centers, Annu. Rev. Earth Planet. Sci., 30, 385-491, 2002.

Kinoshita, M., R. P. Von Herzen, O. Matsubayashi, and K. Fujioka,
Tidally-driven effluent detected by long-term temperature monitoring at the TAG hydrothermal mound, Mid-Atlantic Ridge, Phys. Earth Planet. Int., 109, 201-212, 1998.

Lavelle, J. W. and M. A. Wetzler, Diffuse venting and background contributions to chemical anomalies in a neutrally buoyant ocean hydrothermal plume, J. Geophys. Res., 104, 3201-3209, 1999.

Lunel, T., M. Rudnicki, H. Elderfield, and D. Hydes, Aluminium as a depth-sensitive tracer of entrainment in submarine hydrothermal plumes, Nature, 344, 137-139, 1990.

Middleton, J. H., The rise of forced plumes in a stably stratified crossflow, Boundary-Layer Meteorol., 36, 187-199, 1986.

Morton, B. R., G. I. Taylor, and J. S. Turner, Turbulent gravitational convection from maintained and instantaneous source, Proc. R. Soc. Lond. A, 234, 1-23, 1956

Rudnicki, M. D. and H. Elderfield, Theory applied to the Mid-Atlantic Ridge hydrothermal plumes: the finite-difference approach, J. Volcanol. Geotherm. Res., 50, 161-172, 1992.

Schultz, A. and H. Elderfield, Controls on the physics and chemistry of seafloor hydrothermal circulation, Phil. Trans. R. Soc. London Ser. A, 355, 387-425, 1997.

Speer, K. G. and P. A. Rona, A model of an Atlantic and Pacific hydrothermal plume, J. Geophys. Res., 94, 6213-6220, 1989.

Tivey, M. K., S. E. Humphris, G. Thompson, M. D. Hannington, and P. A. Rona, Deducing patterns of fluid flow and mixing within the TAG active hydrothermal mound using mineralogical and geochemical data, J. Geophys. Res., 100, 12527-12555, 1995.

S. Goto (e-mail: s.gotou@aist.go.jp), T. Gamo, H. Chiba, K. Fujioka and K. Mitsuzawa 